\title{
RESENHA
}

\section{The cold war: a new history*}

Em 1980, ao analisar a historiografia americana de relações internacionais, Charles Maier afirmaria que o campo regredia e estagnava, não tendo o interesse dos estudantes nem a atenção da grande academia do país. ${ }^{1}$ Anos depois, John Lewis Gaddis seguiria na mesma linha ao afirmar, em uma metáfora, que essa pequena e decrescente comunidade de historiadores parecia ocupar, no mundo acadêmico, "algo como o nicho evolucionário ocupado pelo crocodilo [...] e a barata: [esses acadêmicos] estão por perto há muito tempo e não estão em perigo imediato de extinção; mas [são] ainda primitivos e, por esta razão, não muito interessantes." ${ }^{2}$ A crítica não foi restrita aos dois historiadores e durante duas décadas uma crise que pairou sobre o campo parecia apontar para a própria extinção da área - o maior medo nos momentos mais agonizantes era a possibilidade do campo seguir o mesmo rumo da história marítima: a extinção pelas mudanças bruscas da modernização no mundo e na própria disciplina de história. ${ }^{3}$

A chamada Diplomatic History já tinha passado por um período crítico durante a década de 60 quando o pioneiro trabalho de William Appleman Williams implodiria consensos centrais do campo. Williams, que lideraria a chamada escola revisionista (também chamada de Escola de Wisconsin ou new left), afirmaria que o foco nas elites e nos grandes estadistas era equivocado quando se buscava explicar a política externa dos Estados Unidos. Para ele, dever-se-ia concentrar em aspectos internos, notadamente econômicos, que tinham profundo impacto na política externa americana. Dessa forma, essa nova abordagem diminuía o papel dos indivíduos e os efeitos do sistema internacional nas grandes decisões da política externa do país. ${ }^{4} \mathrm{~A}$ revisão no

* Resenha de GADDIS, J. L. The cold war: a new history. New York, The Penguin Press, 2005. ISBN 1594200629 .

** Mestrando em Relações Internacionais pela Universidade de Brasília - UnB (rofarias@gmail.com).

1 (Maier: 1980, 355-8 e 83-87).

2 Gaddis: 1990, 406.

3 (Craig: 1983, Gaddis: 1990, Haber, Kennedy e Krasner: 1997, Hoffman: 1997, Hogan: 1986, Hunt: 1991, Hunt: 1992, Iriye: 1989, Leffler: 1995, McMahon: 1990, Ninkovich: 1991, Sharlet: 1999, Thorne: 1983, Thorne: 1990).

4 (Pelz: 1988, 260, Williams: 1972). 
curso historiográfico foi bastante explícita, principalmente no que se refere ao tópico da Guerra Fria. Enquanto o primeiro grupo de historiadores acusava o desejo de Stalin de dominação da Europa como o aspecto central na origem da Guerra Fria, o grupo subseqüente, liderado por Appleman Williams, argumentava que a Guerra Fria foi, na verdade, uma resultante dos interesses econômicos profundos dos EUA. O debate entre a abordagem tradicional e revisionista ocuparia as páginas dos periódicos especializados, os seminários acadêmicos e as páginas dos jornais de grande circulação.

Foi durante esses debates, quando os historiadores que trabalhavam imersos na área começavam a sentir o declínio da disciplina, que o historiador John Lewis Gaddis lançaria o seu primeiro ataque tanto à concepção de Williams como aos historiadores tradicionais. De acordo com ele, as duas concepçóes eram equivocadas, estando a origem da Guerra Fria no conflito de interesses e misperceptions de ambos os lados da díade primária do conflito. Assim, progressivamente, Gaddis foi ocupando um espaço central nos estudos históricos sobre o período, sendo hoje considerado o maior importante historiador do período. 5 Nota-se, contudo, que nos últimos trabalhos Gaddis tem progressivamente voltado à interpretação tradicional sobre a origem da Guerra Fria, por vezes tendo um radicalismo muito maior na responsabilização de Stalin do que historiadores predecessores. ${ }^{6}$ Para Gaddis, a afirmativa de que se os Estados Unidos tivessem se esforçado no início do pós-guerra em acomodar Moscou a Guerra Fria não teria existido, como vários historiadores das duas correntes anteriores tentaram mostrar, é uma falácia pelo simples fato do Estado stalinista ter tido como fundamento constitutivo a não coexistência com o mundo democrático no longo prazo. ${ }^{7}$

O fim da URSS não colocou um ponto final nesse debate; muito pelo contrário, uma torrente de produção acadêmica tem demonstrando que aspectos centrais do período ainda são controversos. O que tem servido de combustível é a aparente inesgotável fonte de documentos que fluem do leste europeu e da própria Rússia. Isso traz mudanças importantes, já que até pouco tempo historiadores da Guerra Fria trabalhavam sem saber o que estava nos arquivos soviéticos. Tinham que trabalhar, portanto, inferindo as motivações e objetivos da política externa soviética de arquivos americanos, o que dava um grande grau de imprecisão a certos trabalhos. O que tem ocupado os questionamentos do campo agora é de que forma os recentes arquivos abertos afetam o debate sobre a origem e a evolução da Guerra Fria?

\footnotetext{
5 (Gaddis: 1986, Gaddis: 1989, Gaddis: 1990, Immerman: 1988).

${ }^{6}$ Em certos momentos o autor utiliza até certas descrições dispensáveis para justificar essa tese, como o fato de Stalin ter matado o seu papagaio com uma forte batida de seu cachimbo na cabeça do animal ao observar que esse o estava imitando. (Gaddis: 1994, 145).

7 (Ibid.). Gaddis aqui ecoa o seu principal mentor intelectual - George Kennan.

8 (Leffler: 1996, 120).
} 
Várias pesquisadores concordam com a tese de Gaddis que a nova evidência reafirma visões e interpretaçôes mais tradicionais sobre os eventos da Guerra Fria, mas isso não é um consenso; uma leitura mais detida em livros e artigos construídos sobre essas novas fontes primárias tendem a dar uma visão com mais nuance em certos tópicos. Entre as descobertas de maior impacto são as recorrentes conclusões desses trabalhos de que existia um nível de agenciamento muito maior dos lideres comunistas locais do que se supunha, tendo eles, inclusive, em diversos momentos, influenciado importantes decisões realizadas em Moscou. ${ }^{9}$ O projeto de estudo da Guerra Fria, portanto, está ainda em seus primórdios, mas já conta com uma estrutura institucional de peso. Desde 1992, por exemplo, é publicado pelo Cold War International History Project da Woodrow Wilson International Center, um boletim com as novas evidências sobre aspectos centrais da guerra fria. Em Harvard, desde 1999, é publicado pelo Project on Cold War Studies um periódico dedicado somente ao período, iniciativa semelhante da London School of Economics Cold War Studies Centre que edita o periódico Cold War History.

Não obstante essas iniciativas, que potencialmente poderiam dar contornos mais conclusivos a certos pontos dos debates na área, os alunos que agora freqüentam os cursos de graduação nos Estados Unidos estão muito longe da realidade e dos atores da Guerra Fria - Stalin, Truman e Reagan seriam para estes tão distantes quanto Napoleão e Alexandre o Grande, de acordo com Gaddis. ${ }^{10}$ Foi com objetivo de acolher os jovens alunos que esse autor lança, portanto, a obra "The cold war: a new history".

$\mathrm{O}$ texto tem as marcas registradas do atual ocupante da cadeira Robert A. Lovett da Universidade de Yale: a prosa concisa, o senso de humor e a capacidade sempre renovada de surpreender os seus leitores com quadros descritivos bastante sofisticados. Mas uma nota de cautela deve ser dada: para os que se interessam em novidades recém saídas dos arquivos de Praga ou Moscou, esse livro trará poucas, tendo o autor utilizado como fontes somente seus trabalhos anteriores e bibliografia já conhecida - daí o trabalho cumprir seu objetivo de servir mais aos estudantes que os especialistas.

O livro, contudo, vai ser um marco na historiografia americana de relaçōes internacionais. Ele é mais uma grande reversão para a Escola de Winsconsin de William Appleman Williams - que há alguns anos já ocupa a margem da historiografia. O livro, dessa forma, passa longe da suspeição de alguns historiadores de que as fontes motivadoras dos tomadores de decisão americanos estavam nos interesses comerciais e financeiros do país. O desenrolar da Guerra Fria, assim, seria uma complexa combinação de indivíduos, contingente e 'forças tectônicas' que estavam além do alcance de qualquer força motriz unificadora.

9 (Gaddis: 1994, Leffler: 1996, 128-9).

10 (Gaddis: 2005, ix). 
A força dos indivíduos também não está somente nos grandes estadistas, apesar desses serem os protagonistas da narrativa. Os milhares de húngaros que fugiam para a Áustria, e as centenas de cidadãos da Europa Oriental que os acompanharam, ao entrarem pela Hungria após atravessarem a fronteira com a Chechoslováquia, em meados de 1989; assim como personalidades como George Orwell e o então desconhecido Lech Walesa detêm papel de grande relevo no trabalho.

Gaddis também exercita com bastante maestria a capacidade de utilizar contrafactuais para tornar a narrativa mais instigante e colocar com mais clareza o argumento de como o mundo esteve muito mais próximo do colapso nuclear do que se imagina. ${ }^{11}$ Outro aspecto instigante no livro é o papel do poder militar nas relaçóes internacionais. Esse sempre foi um aspecto central na interação entre entidades soberanas no sistema internacional, da Guerra do Peloponeso à Segunda Guerra Mundial. Mas para Gaddis, a Guerra Fria é um marco na história da humanidade; a categoria poder desde então não poderia ser concebida em termos estritamente militares para a sobrevivência de um Estado, afinal, a União Soviética ruiria com toda a sua gigantesca capacidade de infligir danos aos seus adversários. ${ }^{12}$

Esse otimismo ainda é compartilhado nas teses do autor sobre as fontes da supremacia capitalista sobre o totalitarismo comunista. De um lado, de acordo com o autor, demonstrou-se que qualquer forma hierárquica de organização social e econômica fracassaria frente a forma descentralizada e espontânea na qual o capitalismo conseguiu atender às demandas de sua população, mesmo que desigualmente; de outro, a "globalização da democratização" marcou um grau maior de legitimidade que os modos autoritários de gestão governamental. Assim, teria sido a conjunção da explosão democrática e a eficiência dos mercados que marcaria a ruptura "com os determinismos imperiais, ideologias impostas e uso arbitrário da força para a sustentação do poder autoritário". ${ }^{13}$

Observando essas teses do trabalho percebe-se que, acompanhando o momento político doméstico americano, a "nova história" que o autor propóe é a história tradicional, conservadora, ainda centrada à visão de Washington. A forma extremamente simpática que o autor deteve-se no estudo dos presidentes republicanos no livro, com especial carinho à Eisenhower e Reagan, não esconde a forma particular que o historiador vê a Guerra Fria. Talvez por isso Gaddis tenha se tornado o historiador favorito da administração Bush, tendo recebido a medalha National Humanities de 2005 do próprio presidente.

\footnotetext{
${ }^{11}$ Ver um exemplo bastante instigante no início do segundo capítulo (Ibid., 48).

12 (Ibid., 261-3).

13 (Ibid., 265-6).
} 
O livro, apesar de sobrepujar as interpretaçōes revisionistas da Guerra Fria, demonstra como a diplomatic history tradicional americana ainda encontra seus flancos abertos às críticas que marginalizaram o campo até meados da década de 90 . Nas mais de 250 páginas do livro o autor não cita nenhuma fonte em outra língua que não o inglês e sua abordagem ainda é essencialmente paroquial, voltada aos problemas da política externa americana - o que é estranho dado os esforços na área em superar as críticas de Charles Maier e do próprio autor. ${ }^{14} \mathrm{O}$ entendimento de como a Guerra Fria moldou as sociedades, práticas culturais e a política doméstica dos Estados Unidos e de outros países, portanto, é algo que passa longe dessa "nova (velha) história". Não obstante, "The Cold War: a new history" é hoje o melhor manual para os interessados em entender os importantes dilemas desse período fundamental da política internacional do século XX.

\section{Bibliografia}

BlantOn, ThOmas S. The end of history? The beginning of global perspective? The threat of sources. Passport: The Newsletter of the Society for Historians of American Foreign Relations, $\mathrm{n}$. March, 1.12.2005, p. 2003.

Craig, Gordon A. The historian and the study of international relations. The American Historical Review, v.88, n. 1, p. 1-11. 1983.

EDITOR. Editor's note. Journal of Cold War Studies, v.1, n. 1, p. 1-2. 1999.

GADDIS, JOHN LEWIS. The corporatist synthesis: a skeptical view. Diplomatic History, v.10, n. 4 (Fall), p. 357-62. 1986.

. Intelligence, Espionage, and Cold War Origins. Diplomatic History, v.13, n. 2 (Spring), p. 191-212. 1989.

. New conceptual approaches to the study of American Foreign Relations: interdisciplinary perspectives. Diplomatic History, v.14, n. 3 (Summer), p. 405-23. 1990.

. The tragedy of Cold War history. Foreign Affairs, v.73, n. 1, p. 142-54. 1994.

. The cold war: a new history. New York: The Penguin Press, 2005.

HABER, STEPHEN H., KENNEDY, DAVID M., et al. Brothers under the skin: diplomatic history and international relations. International Security, v.22, n. 1, p. 34-43. 1997.

Hoffman, Elizabeth COBBS. Diplomatic history and the meaning of life: toward a global American history. Diplomatic History, v.21, n. 4, p. 499-518. 1997.

14 (Blanton: 2003, Hoffman: 1997, Hogan: 2004, Kammen: 2003, Schulzinger: 2004, Sharlet: 1999, Stoler: 2004). 
Hogan, Michael J. Corporatism: a positive appraisal. Diplomatic History, v.10, n. 4 (Fall), p. 363-72. 1986.

The "next big thing": the future of diplomatic history in a global age. Diplomatic History, v.28, n. 1, p. 1-21. 2004.

HUNT, MiCHAEL H. Internationalizing US diplomatic history: a practical agenda. Diplomatic History, v.15, n. 1 (Winter), p. 1-11. 1991.

The long crisis in US diplomatic history: Coming to closure. Diplomatic History, v.16, n. 1 (Winter), p. 115-40. 1992.

IMMERMAN, RICHARD H. In search of history - and relevancy: breaking through the "Encrustations of Interpretations". Review of the book "John Lewis Gaddis. The long peace: inquiries into the history of the cold war. New York: Oxford University Press, 1987." Diplomatic History, v.12, n. 3 (Summer), p. 341-56. 1988.

IRIYE, AKIRA. The internationalization of history. The American Historical Review, v.94, n. 1, p. 1-10. 1989.

KAMMEN, MiCHAEL. Clio, Columbia and the cosmopolitans: beyond American exceptionalism and the nation-state. History and Theory, v.42, n. 1, p. 106-15. 2003.

LEFFLER, MELVYN P. New approaches, old interpretations, and prospective reconfigurations. Diplomatic History, v.19, n. 2, p. 173-96. 1995.

. Inside enemy archives: the Cold War reopened. Foreign Affairs, v.75, n. 4, p. 120-35. 1996.

MAIER, CHARLES S. Marking time: the historiography of international relations. In: The Past before Us: Contemporary Historical Writing in the United States. New York: Cornell University Press, 1980. p. 355-87.

MCMAHON, ROBERT J. The study of American Foreign Relations: national history or international history? Diplomatic History, v.14, n. 4 (Fall), p. 554-64. 1990.

Diplomatic History and Policy History: Finding Common Ground. The Journal of Policy History, v.17, n. 1, p. 93-109. 2005.

NinKOVICH, FrANK. The end of diplomatic history? Diplomatic History, v.15, n. 3 (Summer), p. 439-48. 1991.

PELZ, STEPHEN E. A taxonomy for American diplomatic history. Journal of Interdisciplinary History, v.19, n. 2, p. 259-76. 1988.

SCHUlzINGer, RoberT D. Diplomatic History and American Studies. Passport: The Newsletter of the Society for Historians of American Foreign Relations, n. August, 1/12/2005, p. 2004.

SHARLET, JEFF. Why diplomatic historians may be victims of American triumphalism? Disponível em: <http://chronicle.com/colloquy/99/dhistory/background.htm>. Acesso em: $1 / 12 / 2005$.

SOFFER, JONATHAN. Oral history and the history of American foreign Relations. The Journal of American History, v.82, n. 2, p. 607-16. 1995. 
STOLER, MARK A. Thoughts from SHAFR president. Passport: The Newsletter of the Society for Historians of American Foreign Relations, n. August, 1/12/2005, p. 2004.

THORne, CHRISTOPHER. International relations and the promptings of history. Review of International Studies, v.9, n. 2, p. 123-35. 1983.

. Diplomatic history: some further reflections. Diplomatic History, v.14, n. 4 (Fall), p. 602-5. 1990.

Williams, William ApPleman. The tragedy of american diplomacy. $2 \mathrm{~d}$ rev. and enl. ed. New York: The Free Press, 1972. 